
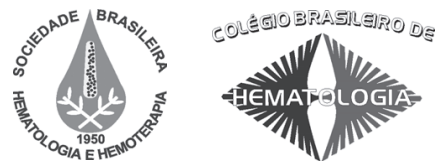

\title{
Terapia celular no acidente vascular cerebral
}

\section{Cell therapy in strokes}

\author{
Rosalia Mendez-Otero ${ }^{I}$ \\ Arthur Giraldi-Guimarães ${ }^{2}$ \\ Pedro M. Pimentel-Coelho ${ }^{3}$ \\ Gabriel R. Freitas ${ }^{4}$
}

\begin{abstract}
O AVC é o recordista em número de óbitos e a maior causa de incapacidade no Brasil. Apesar das inúmeras pesquisas realizadas ao longo dos últimos anos não há terapias farmacológicas adequadas para este quadro e, neste cenário, as terapias celulares vêm sendo consideradas como alternativas terapêuticas para diminuir as perdas funcionais decorrentes do AVC. Nesta revisão comentaremos os resultados de diversos estudos pré-clinicos e de alguns clínicos que utilizaram diferentes tipos de célulastronco em AVC. Rev. Bras. Hematol. Hemoter. 2009;31(Supl. 1):99-103.
\end{abstract}

Palavras-chave: Células-tronco; terapias celulares; isquemia cerebral; neuroproteção; acidente vascular cerebral.

\section{Introdução}

As doenças que acometem o Sistema Nervoso Central (SNC) figuram entre as de maior prevalência, mortalidade e morbidade, tanto em países desenvolvidos como em desenvolvimento, e dentre todas destaca-se o acidente vascular cerebral (AVC). Estima-se que cerca de 18 milhões de pessoas terão um AVC em 2015 e aproximadamente 1/3 destes resultará em óbitos. As análises indicam que, na próxima década, devido ao envelhecimento progressivo das populacões e ao não controle dos fatores de risco, a mortalidade por AVC aumentará $20 \%$ nos paises em desenvolvimento e $10 \%$ nos paises desenvolvidos. No Brasil, dados do SUS mostram que os AVCs (isquêmicos e hemorrágicos) representam a maior causa de morte com cerca de 90 mil casos/ano. Além da alta mortalidade, o AVC representa a maior causa de incapacitacão em adultos, gerando um alto gasto para os sistemas de saúde. ${ }^{1,2}$

Apesar das inúmeras pesquisas pré-clinicas e clínicas realizadas ao longo dos últimos anos, até o momento, a única terapia farmacológica aprovada para o AVC é o uso de trombolítico, que é administrado nas primeiras três horas após o início dos sintomas. No entanto, devido a esta curta janela de tratamento e outras limitacões no seu uso, menos de 3\% dos pacientes recebe esta terapia. Após a fase aguda do AVC, algum grau de recuperação funcional espontânea ocorre ao longo dos meses, porém, a maioria dos pacientes permanece com diversos graus de comprometimento funcional.

O objetivo terapêutico na fase aguda e subaguda do AVC é proteger os neurônios em risco, enquanto, após este período, as terapias visam principalmente aumentar a capacidade de regeneração endógena do SNC e consequentemente diminuir as sequelas funcionais. Neste cenário, as terapias celulares vêm sendo consideradas como possíveis alternativas terapêuticas para tratar doenças para as quais não há no momento tratamentos farmacológicos adequados, incluindo aí doenças neurológicas e, mais especificamente, o AVC.

\section{Células-tronco e terapias celulares}

Células-tronco são células capazes de originar células semelhantes a elas (autorrenovação) e também podem dar origem a diferentes tipos celulares. De acordo com o local de

${ }^{1}$ Professora Titular do Instituto de Biofisica Carlos Chagas Filho, Programa de Terapias Celulares/Protecel - UFRJ - Rio de Janeiro-RJ.

${ }^{2}$ Professor Associado da Universidade Estadual do Norte Fluminense Darcy Ribeiro - Campos dos Goytacazes-RJ.

${ }^{3}$ Médico, Instituto de Ciências Biomédicas, UFRJ, Rio de Janeiro-RJ.

${ }^{4}$ Médico neurologista. Departamento de Neurologia Universidade Federal Fluminense - Niterói-RJ.

Universidade Federal do Rio de Janeiro (UFRJ) - Rio de Janeiro-RJ.

Correspondência: Rosalia Mendez-Otero

Instituto de Biofisica Carlos Chagas Filho

Av. Carlos Chagas Filho 373

21941-590 - Cidade Universitária - Rio de Janeiro-RJ - Brasil

Tel: (55 21)2562-6554 / Fax: (55 21) 2280-8193

E-mail:rmotero@biof.ufrj.br

Doi: 10.1590/S1516-84842009005000030 
origem e, principalmente, com a sua capacidade de diferenciação, são classificadas como totipotentes (zigoto), pluripotentes (como, por exemplo, as embrionárias, as germinativas, e as induzidas) e multipotentes ou células-tronco adultas (sangue de cordão umbilical, células de medula óssea ou dos tecidos do adulto). ${ }^{3}$

As células-tronco embrionárias humanas são obtidas a partir da massa celular interna de blastocistos. Devido à sua alta capacidade de autorrenovação, que permite a obtenção de um número elevado de células, e à sua pluripotencialidade, dando origem a células de todos os tecidos, estas células são consideradas a fonte ideal para terapias celulares que visem a substituição de tecidos perdidos em lesões ou doenças. ${ }^{4,5}$ No entanto, muitos problemas devem ser resolvidos antes que estas células venham a ser usadas em terapias para pacientes. Devido à sua instabilidade genômica, frequentemente ocorrem alterações no cariótipo destas células após várias passagens in vitro. Além disto, quando introduzidas em modelos animais, mesmo após pré-diferenciação em fenótipos específicos, estas células podem formar teratomas. Devido a estes e outros fatores, no momento não há tratamentos utilizando células-tronco embrionárias para repor tecidos degenerados ou lesados e se acredita que ainda serão necessários alguns anos para que os inúmeros estudos pré-clinicos cheguem a resultados que possam ser transferidos para a prática clínica.

As células-tronco adultas têm baixo potencial de proliferação e são consideradas menos potentes, pois, em geral, só dão origem às células do tecido do qual foram obtidas. Nesta categoria estão incluídas as células de sangue de cordão umbilical, as de medula óssea e as células-tronco existentes dentro de cada tecido adulto, incluindo o sistema nervoso. No caso das células-tronco adultas, as que vêm sendo mais utilizadas, tanto em estudos pré-clínicos como nos poucos estudos clínicos em andamento, são as células de medula óssea. ${ }^{6,7}$

A medula óssea é uma fonte permanente de célulastronco pluripotentes, que podem originar não somente linhagens celulares hematógenas e mesenquimais (osso, cartilagem, adipócitos), mas também células de vasos sanguíneos (musculares lisas e endoteliais). ${ }^{8}$ Inicialmente, acreditava-se que as células de medula óssea poderiam dar origem a células de diferentes tecidos, incluindo neurônios e glia. No entanto, mais recentemente vem-se demonstrando que a capacidade de transdiferenciação em células do sistema nervoso e a fusão destas células a outras, como neurônios, por exemplo, são muito restritas e seu uso, portanto, não teria benefícios terapêuticos. ${ }^{9,10}$ Por outro lado, as células-tronco de medula óssea apresentam diversas características que podem ser exploradas terapeuticamente. Uma dessas características é o tropismo que se apresentam por áreas de injúria tecidual.

Outra característica importante é que estas células produzem diversos fatores tróficos. Estes fatores melhoram o funcionamento de neurônios, promovem maior sobrevida dos mesmos, diminuem a inflamação e aumentam a vasculogênese. As terapias com células-tronco de medula óssea visam, portanto, proteger os neurônios que ainda restam, ao invés de substituir os que já foram perdidos em uma determinada lesão ou doença.

\section{Terapia celular em doenças neurológicas}

O sistema nervoso apresenta determinadas características que tornam as terapias celulares particularmente difíceis, principalmente se o objetivo que se tem em mente é a utilização de células-tronco para substituir células perdidas em uma determinada doença ou lesão neurológica. As principais células do sistema nervoso (neurônios e glia) se originam do ectoderma enquanto a microglia se origina do mesoderma. Os neurônios processam e transmitem a informação e já foram descritos mais de 32 diferentes tipos de neurônios que diferem entre si tanto pelas características morfológicas como funcionais. Alguns, como os motoneurônios, que inervam a musculatura estriada dos membros inferiores, apresentam o corpo celular nos segmentos lombares da medula espinhal e um axônio que se estende por vários centímetros (em alguns indivíduos por mais de um metro) até o seu local de inervação no músculo estriado esquelético. Para tratar doenças que comprometem especificamente este neurônio, como é o caso, por exemplo, da esclerose lateral amiotrófica, a célula-tronco a ser utilizada deverá não somente se diferenciar em motoneurônios, mas também ser capaz de emitir um axônio que navegue até o local a ser inervado e só então a funcão motora poderia ser restaurada. Por outro lado, em outras doenças, a perda celular é limitada a uma região e a um tipo específico de neurônio, como é o caso da doença de Parkinson. Neste caso, a diferenciação de células-tronco em neurônios dopaminérgicos poderia substituir as células perdidas com mais facilidade e possivelmente poderia restaurar parte da função perdida.

Uma outra característica importante do SNC a ser considerada é a sua pequena capacidade de regeneração. Até o início da década de 60 , acreditava-se que novos neurônios não eram formados no SNC de adultos. A partir desta época inúmeras evidências experimentais mostram a formação de novos neurônios continuamente e a presença das denominadas células-tronco neurais no cérebro de indivíduos adultos em pelo menos duas regiões: a zona subventricular, em torno dos ventrículos laterais, e a camada subgranular do giro dentado do hipocampo. Estas células estão presentes em número reduzido, dividem-se lentamente e podem dar origem a neurônios e glia. As evidências sugerem que as células-tronco neurais adultas são remanescentes das célulastronco neurais presentes durante o período embrionário, uma vez que apresentam muitas características e marcadores em comum. ${ }^{11}$

A presença destas células, embora em número reduzido e em regiões limitadas, abriu novas perspectivas e permitiu que novas estratégias fossem desenvolvidas no reparo de lesões do SNC. Em teoria, seria possível estimular estas 
células de modo a que mais neurônios e/ou glia fossem gerados, assim como poderia ser possível ativá-las de tal forma que tipos neuronais específícos pudessem ser gerados. Embora animadoras, estas possibilidades ainda permanecem como hipóteses, uma vez que o conhecimento sobre os mecanismos e fatores que interferem na proliferação, migração e diferenciação destas células ainda devem ser investigados, tanto em modelos animais como em primatas, incluindo o homem. A perspectiva é que venha a ser possível utilizar as células-tronco neurais do próprio indivíduo para substituir neurônios especifícos e/ou células gliais perdidos em uma determinada doença ou lesão do sistema nervoso. Para isso, estas células poderiam ser retiradas por biópsia, expandidas in vitro, diferenciadas no tipo celular específico desejado e reintroduzidas na área ou região afetada visando restaurar a função. Este cenário promissor depende, no entanto, do progresso de estudos experimentais que ainda estão, na sua maioria, em fases iniciais.

Praticamente todos os tipos de células-tronco descritos até momento vêm sendo investigados em modelos animais de doenças neurológicas e em muitos destes estudos os resultados são promissores no que diz respeito à segurança e à eficácia. A partir do isolamento das primeiras linhagens de células-tronco embrionárias humanas no final da década de 90 , foram publicados vários protocolos que permitem a diferenciação destas células em neurônios específicos (dopaminérgicos, motoneurônios, gabaérgicos, etc.) e em células de glia (astrócitos e oligodendrócitos). Estas células pré-diferenciadas têm sido introduzidas em modelos animais de doenças neurológicas e, em muitas das vezes, os resultados mostram uma melhora funcional.

\section{Terapia celular em modelos animais de AVC}

O modelo mais utilizado tem sido a obstrução permanente ou temporária da artéria cerebral média (MCAO, do inglês middle cerebral artery occlusion). Neste modelo, a análise histológica da área cerebral infartada apresenta uma região central (centro) onde ocorre morte por necrose e uma região periférica (penumbra) na qual células em apoptose podem ser observadas por vários dias após a isquemia. Em testes de comportamento motor, o animal apresenta diferentes graus de comprometimento funcional no lado contralateral à isquemia.

Diferentes tipos de células-tronco têm sido utilizadas neste modelo e a avaliação de sua eficácia tem sido feita através da análise histológica do volume de infarto e/ou da melhora funcional. Em alguns estudos foram avaliados também os efeitos das células injetadas na formação de novos vasos, na diminuição da astrocitose ou na modulação da neurogênese a partir das células-tronco neurais. Ainda neste mesmo modelo foram relatadas evidências de diferenciação das células injetadas (no caso de células pluripotentes) em células do sistema nervoso central (neurônios, astrócitos e microglia). ${ }^{12,13}$ Além do tipo celular mais adequado para esta terapia, o número de células injetadas e a via de aplicação das mesmas tem sido motivo de diversos estudos. Praticamente todas as vias possíveis foram utilizadas experimentalmente e, até o momento, não há nenhum consenso na literatura em relação a qual (is) seria (m) a(s) melhor(es) via(s) também, bem como não se sabe se haveria um número mínimo ou máximo de células a serem utilizadas.

Apesar destes pontos ainda controversos, a maioria dos estudos aponta para uma melhora morfológica (menor volume de infarto, menor astrogliose, aumento na neurogênese, aumento na vascularização) e uma menor perda funcional nos animais que receberam a terapia celular.

Os estudos pré-clínicos são importantes para avaliar o mecanismo de ação, o tipo celular mais adequado, a dose, a via de administração, a migração, homing e diferenciação das células injetadas e a partir destes resultados são desenhados os estudos clínicos.

Os resultados de diversos estudos pré-clínicos sugerem que células derivadas de medula óssea apresentam um efeito benéfico na recuperação funcional de animais isquêmicos quando injetadas por via intravenosa, intra-arterial ou intracerebral. Os autores sugerem que o mecanismo de ação possivelmente envolve ações tróficas das células injetadas, resultando em aumento da angiogênese, neurogênese e sinaptogênese, com consequente aumento no remodelamento do $\mathrm{SN}$ e melhora funcional. ${ }^{14}$

A vantagem da utilização destas células em relação a outros tipos é a possibilidade de terapia celular com células retiradas da medula óssea do próprio paciente, o que elimina todas as questões éticas e de disponibilidade. Células do sangue de cordão umbilical humano também foram utilizadas em modelos de AVC com resultados funcionais semelhantes aos das células da medula óssea. Além disto, foi sugerido que as células de cordão podem exercer seu efeito benéfico mesmo sem entrar no parênquima cerebral, sugerindo que a liberação de fatores e não a diferenciação seja o mecanismo predominante. Uma outra observação importante é a de que as células de sangue de cordão diminuem a ativação do baço e poderiam exercer o seu papel, pelo menos parcialmente, por um mecanismo imunossupressivo e/ou modulando a inflamação e a resposta imune após o AVC. ${ }^{14,15}$

Além das células de medula e cordão, todos os tipos celulares que têm sido investigados secretam diversos fatores tróficos como VEGF (vascular endothelial growth factor) e BDNF (brain derived nerve growth factor) por exemplo, além de outros fatores neuroprotetores e citocinas.

Uma das questões que devem ser ainda investigadas diz respeito à janela terapêutica adequada para a aplicação da terapia celular. Foi sugerido que, entre 24 horas e um mês após o AVC, a via ideal de administração das células deveria ser intravascular (intra-arterial ou endovenosa). As células administradas por estas vias poderiam ser atraídas até o local de lesão devido à presença de citocinas, como, por exemplo, 
SDF-1 (stroma derived factor 1) liberado pelo tecido lesado. Células de medula óssea expressando os receptores CXCR4 e CXCR7 seriam atraidas seletivamente para o local rico em SDF-1. Já foi demonstrado em roedores que o SDF-1 é produzido no local da isquemia pelo menos até um mês após a lesão. Após este período, foi sugerido que a via intracerebral poderia ser a mais adequada.

Outras vantagens da terapia celular com células autólogas incluem a ausência de rejeição e o seu pequeno potencial de diferenciação, o que minimiza a possibilidade de formação de tumores. As células de medula óssea têm sido utilizadas logo após a retirada da medula (a denominada fração mononuclear) ou após diversas etapas de expansão em cultura (células mesenquimais de medula óssea) tanto nos modelos animais como nos poucos estudos clínicos descritos a seguir. A vantagem de se utilizarem células da fração mononuclear em relação às mesenquimais é o fato de que as primeiras não exigem manipulações prolongadas, o que as torna mais seguras, principalmente em estudos clínicos com um grande número de pacientes. Além disto, a expansão de células de medula óssea para obtenção de células mesenquimais exige várias semanas de cultivo, o que pode significar que o paciente não estará mais na janela terapêutica adequada para a terapia.

\section{Terapia celular em pacientes com AVC}

Há duas abordagens básicas nas terapias celulares em pacientes com AVC. A primeira se baseia na mobilização de células endógenas através de fatores tróficos. Os dois fatores que têm sido utilizados são a eritropoietina (EPO) e o fator estimulador da formação de colônias de granulócitosmacrófagos (G-CSF).

A outra possibilidade utiliza células exógenas para substituir células perdidas e/ou para liberar fatores tróficos e neuroprotetores que possam diminuir a perda tecidual e contribuir para a regeneração. ${ }^{?}$

Até o momento, apenas alguns estudos clínicos utilizando terapias celulares em pacientes com AVC foram concluídos e os resultados publicados. Nestes estudos, diferentes tipos de células foram utilizadas assim como as terapias foram realizadas em diferentes fases do AVC, o que impossibilita qualquer comparação entre os mesmos. Além disto, a maioria destes estudos teve por objetivo avaliar a segurança e, portanto, nada pode ser afirmado em relação à eficácia das diferentes terapias.

Em um desses estudos, células provenientes de uma linhagem neuronal derivada de um teratocarcinoma humano foram implantadas estereotaxicamente em pacientes com infarto subcortical crônico (seis meses a seis anos após o AVC). Em uma série de publicações, os autores relatam que não houve efeitos adversos relacionados às células implantadas. A avaliação funcional utilizando a escala de avaliação européia mostrou uma melhora média de 2,9 pontos. O PET realizado seis meses após a terapia mostrou uma maior atividade metabólica na área peri-infarto em seis dos onze pacientes, o que poderia corresponder a melhora funcional. Um dos pacientes veio a falecer 27 meses após a terapia por causas não relacionadas ao tratamento, e a análise neuropatológica mostrou numerosos neurônios derivados do transplante no local da injeção. Os autores concluem que a terapia com estas células parece ser segura e exequível em pacientes com infartos subcorticais. Um estudo fase II randomizado foi realizado com 18 pacientes 1-6 anos após AVCs de gânglios da base e, portanto, apresentavam perdas funcionais fixas e estáveis. Os pacientes foram randomizados para receber duas doses diferentes de células ou não receber as células $(n=4)$ e todos foram mantidos em programas de reabilitação. Os resultados mostraram que o transplante foi seguro, porém não houve nenhuma melhora na pontuação avaliada pelo European Stroke Score entre os grupos tratados e não tratados seis meses após o transplante. No entanto, houve melhoras significativas em alguns outros parâmetros funcionais avaliados, como, por exemplo, o Action Arm Test e o Everyday Memory Test. . $^{17,18}$

Em outro estudo fase I já finalizado, cinco pacientes com AVC isquêmico de artéria cerebral média receberam um total de $1 \times 10^{8}$ celulas mesenquimais de medula óssea autólogas divididas em duas doses 4-5 e 7-9 semanas após o AVC. A terapia foi segura, exequível e os pacientes tratados apresentaram uma melhora no índice de Barthel e na escala modificada de Rankin quando comparados a um grupo controle $(\mathrm{n}=25)$. Não houve diferença entre os dois grupos em relação ao tamanho do infarto, mas aparentemente houve uma menor atrofia na área peri-infarto no grupo tratado e uma dilatação menor dos ventrículos. ${ }^{19}$

No Brasil, em um estudo conjunto do Hospital Prócardíaco (RJ) e da Universidade Federal do Rio de Janeiro (Serviço de Neurologia e Instituto de Biofísica Carlos Chagas Filho) foi avaliada a segurança do transplante de células mononucleares na fase aguda do AVC isquêmico. Sete pacientes com AVC isquêmico no território da artéria cerebral média até dez dias após o evento, com NIHSS entre 4 e 20 e com demonstração por Doppler transcraniano (DTC), ou angiorressonância da permeabilidade da artéria cerebral média ipsilateral foram incluídos. Os pacientes foram acompanhados com avaliações neurológicas seriadas (NIHSS, IB e EMR), por exames de sangue e por RM, SPECT (singlephoton emission computed tomography) e PET. Entre três e dez dias após o AVC, foi realizada punção da medula óssea na crista ilíaca posterior após anestesia local com ou sem sedação. As células mononucleares foram isoladas e cerca de quatro horas depois foram administradas 30 milhões de células mononucleares na área cerebral afetada através de arteriografia cerebral. O procedimento foi monitorado para a ocorrência de embolia através de DTC e para atividade elétrica convulsiva com eletroencefalograma. Um paciente apresentou embolia e AVC isquêmico durante a arteriografia e 
não recebeu as células-tronco. Dos seis pacientes que receberam as células mononucleares, nenhum teve piora clínica, alterações hematológicas ou surgimento de imagens na RM de crânio em um seguimento de seis meses. Todos os pacientes apresentaram melhora neurológica mensurada através do NIHSS, IB e EMR. Em um dos pacientes, cerca de 5\% das células mononuclares foram marcadas com tecnécio para avaliar sua distribuição. Exame de SPECT cerca de 24 horas após a administração mostrou acúmulo das células no hemisfério cerebral afetado, na área isquêmica e na região peri-infarto. Avaliações iniciais dos exames de PET e SPECT mostraram aumento do metabolismo cerebral após a administração das células. $^{20-23}$

Protocolo semelhante foi conduzido na Pontifícia Universidade Católica de Porto Alegre e no Hospital Mãe de Deus (RS), incluindo vinte pacientes. Algumas diferenças merecem menção: o número de células administrado foi maior (máximo de 500 milhões), pacientes com NIHSS maior de que 20 foram incluídos e todos os pacientes tinham infartos maiores que um terço do território da artéria cerebral média (Maurício Friederich, comunicação pessoal). Análise conjunta dos seis pacientes do primeiro estudo com os vinte pacientes do grupo do RS reforçou os dados de segurança, sem piora neurológica após o transplante.

Concluindo, os resultados de estudos iniciais com células-tronco autólogas são animadores. Ensaios fase II com maior número de pacientes e com grupo controle são necessários.

\section{Abstract}

Stroke is the leading cause of death and incapacity in Brazil. Over the last few years, numerous preclinical and clinical studies have been carried out, however to date, none of the drugs tested in these studies were effective in patients. The emerging field of stem cell research has raised hope of therapy to ameliorate the functional loss after strokes. In this review we will discuss the results of several preclinical studies and clinical trials using different types of stem cells in the treatment of strokes. Rev. Bras. Hematol. Hemoter. 2009; 31(Supl. 1):99-103.

Key words: Stem cells; cell therapies; cerebral ischemia; neuroprotection; stroke.

\section{Referências Bibliográficas}

1. Strong K, Mathers C, Bonita R. Preventing stroke: saving lives around the world. Lancet Neurol. 2007;6(2):182-7.

2. André C, Curioni CC, Braga da Cunha C, Veras R. Progressive decline in stroke mortality in Brazil from 1980 to 1982,1990 to 1992, and 2000 to 2002. Stroke. 2006;37(11):2784-9.

3. Fuchs E, Segre JA. Stem cells: a new lease on life. Cell. 2000; 100 (1):143-55

4. Weissman IL. Stem cells: units of development, units of regeneration, and units in evolution. Cell. 2000;100(1):157-68.

5. Thomson JA, Itskovitz-Eldor J, Shapiro SS, Waknitz MA, Swiergiel JJ, Marshall VS, et al. Embryonic stem cell lines derived from human blastocysts. Science. 1998;282(5391):1145-7.
6. Mezey E. Bone marrow-derived stem cells in neurological diseases: stones or masons? Regen Med. 2007;2(1):37-49.

7. Mendez-Otero R, de Freitas GR, André C, de Mendonça ML, Friedrich M, Oliveira-Filho J. Potential roles of bone marrow stem cells in stroke therapy. Regen Med. 2007;2(4):417-23.

8. Kørbling M, Estrov Z. Adult stem cells for tissue repair - a new therapeutic concept? N Engl J Med. 2003;349(6):570-82.

9. Crain BJ, Tran SD, Mezey E. Transplanted human bone marrow cells generate new brain cells. J Neurol Sci. 2005;233(1-2):121-3.

10. Alvarez-Dolado M, Pardal R, Garcia-Verdugo JM, Fike JR, Lee HO, Pfeffer K, et al. Fusion of bone-marrow-derived cells with Purkinje neurons, cardiomyocytes and hepatocytes. Nature. 2003;425 (6961):968-73.

11. Alvarez-Buylla A, Lim DA. For the long run: maintaining germinal niches in the adult brain. Neuron. 2004;41(5):683-6.

12. Bliss T, Guzman R, Daadi M, Steinberg GK. Cell transplantation therapy for stroke. Stroke. 2007;38(2 Suppl):817-26.

13. Caplan AI. Adult mesenchymal stem cells for tissue engineering versus regenerative medicine. J Cell Physiol. 2007;213(2):341-7.

14. Chopp M, Li Y. Treatment of neural injury with marrow stromal cells. Lancet Neurol. 2002;1(2):92-100.

15. da Silva Meirelles L, Caplan AI, Nardi NB. In search of the in vivo identity of mesenchymal stem cells. Stem Cells. 2008;26(9):2287-99.

16. Giordano A, Galderisi U, Marino IR. From the laboratory bench to the patient's bedside: an update on clinical trials with mesenchymal stem cells. J Cell Physiol. 2007;211(1):27-35.

17. Kondziolka D, Steinberg GK, Wechsler L, Meltzer CC, Elder E, Gebel J, et al. Neurotransplantation for patients with subcortical motor stroke: a phase 2 randomized trial. J Neurosurg. 2005; 103 (1):38-45.

18. Hara K, Yasuhara T, Maki M, Matsukawa N, Masuda T, Yu SJ, et al. Neural progenitor NT2N cell lines from teratocarcinoma for transplantation therapy in stroke. Prog Neurobiol. 2008;85(3): 318-34.

19. Bang OY, Lee JS, Lee PH, Lee G. Autologous mesenchymal stem cell transplantation in stroke patients. Ann Neurol. 2005;57(6): 874-82.

20. Mendonça ML, Freitas GR, Silva SA, Manfrim A, Falcão CH, Gonzáles C, et al. Safety of intra-arterial autologous bone marrow mononuclear cell transplantation for acute ischemic stroke. Arq Bras Cardiol. 2006;86(1):52-5.

21. Correa P, Felix R, Mendonca ML, Freitas G, Azevedo J, Dohmann $\mathrm{H}$, et al. Dual-head coincidence gamma camera FDG-PET before and after autologous bone marrow mononuclear cell implantation in ischaemic stroke. Eur J Nucl Med Mol Imaging. 2005;32(8):999.

22. Correa PL, Mesquita CT, Felix RM, Azevedo JC, Barbirato GB, Falcão $\mathrm{CH}$, et al. Assessment of intra-arterial injected autologous bone marrow mononuclear cell distribution by radioactive labeling in acute ischemic stroke. Clin Nucl Med. 2007;32(11):839-41.

23. de Freitas GR, Mendonça MLF, Bezerra DC, et al. Safety and feasibility of intra-arterial autologous bone marrow mononuclear cell transplantation in acute ischemic stroke. Stroke 2006; 37;624-5.

Suporte financeiro: Os autores receberam auxílios do CNPq, Faperj, Capes para os estudos pré-clínicos e o estudo clínico foi financiado pelo auxílio Proc. 552201/2005-7 do Edital CT-Biotecnologia/MCT/CNPq/ MS/SCTE/DECIT -24/2005.

Avaliação: O tema apresentado consta da pauta elaborada pelo editor, Professor Milton Artur Ruiz e coeditores deste suplemento, Professores Sergio Paulo Bydlowski e Adriana Seber.

Conflito de interesse: não declarado

Recebido: 28/08/2008

Aceito: 03/11/2008 